TITLE:

\title{
Mitochondrial Cytochrome $b$ Phylogeny and Historical Biogeography of the Tohoku Salamander, Hynobius Lichenatus (Amphibia, Caudata)
}

\section{$\operatorname{AUTHOR}(\mathrm{S}):$}

Aoki, Gen; Matsui, Masafumi; Nishikawa, Kanto

\section{CITATION:}

Aoki, Gen ...[et al]. Mitochondrial Cytochrome b Phylogeny and Historical Biogeography of the Tohoku Salamander, Hynobius Lichenatus (Amphibia, Caudata). Zoological Science 2013, 30(3): 167-173

\section{ISSUE DATE:}

2013-03

\section{URL:}

http://hdl.handle.net/2433/216899

RIGHT:

(C) 2013 Zoological Society of Japan 


\title{
Mitochondrial Cytochrome b Phylogeny and Historical Biogeography of the Tohoku Salamander, Hynobius lichenatus (Amphibia, Caudata)
}

\author{
Gen Aoki, Masafumi Matsui ${ }^{*}$, and Kanto Nishikawa \\ Graduate School of Human and Environmental Studies, Kyoto University, \\ Yoshida Nihonmatsu-cho Sakyo-ku, Kyoto 606-8501, Japan
}

\begin{abstract}
The Tohoku salamander, Hynobius lichenatus Boulenger, 1883, is a lentic breeding species widespread throughout montane regions of northeastern Japan. To explore intraspecific genetic variation and infer evolutionary history of $\boldsymbol{H}$. lichenatus, we performed mitochondrial DNA analysis (complete 1141 bp sequences of the mitochondrial cytochrome b gene) using 215 adult and larval individuals collected from $\mathbf{7 5}$ localities, encompassing known distributional range of the species. Hynobius lichenatus proved to be monophyletic, including three well-supported and geographically structured clades (Clade I from northern Kanto, Clade II from southern Tohoku, and Clade III from northern Tohoku). These clades, respectively, comprise several subclades, and show genetic distances as large as those seen between different species of Hynobius. Results of population statistic analyses indicate that all clades and most subclades have maintained high genetic diversity and demographic stability over long periods. Molecular dating indicates divergence in $\boldsymbol{H}$. lichenatus concords with topographic evolution of northeastern Japan from late Miocene to early Pleistocene, suggesting that paleogeographic events in this region, such as orogenesis, sea level change, and volcanic activity, have been crucial for shaping genetic patterns and diversity in this species. Hynobius lichenatus greatly differs from many other animal species from northeastern Japan in its much older periods and the pattern of genetic differentiation, and is suggested as an old faunal element in this region.
\end{abstract}

Key words: Hynobius lichenatus, genealogy, biogeography, mitochondrial DNA, cytochrome b, salamander

\section{INTRODUCTION}

Hynobius lichenatus Boulenger, 1883 is a lentic breeding small salamander widely occurring throughout montane regions of northeastern Japan. Several studies have been conducted on the morphology (Inukai and Makino, 1933; Sato, 1943; Aoki, 1977; Maruyama, 1977; Hasumi and Iwasawa, 1987a, b, 1988, 1993), isozymes (Matsui, 1987), Southern blotting (Kuro-o et al., 1992), and mitochondrial DNA (mtDNA) (Matsui et al., 2007) of this species.

In morphological studies, great variations have been detected among and within populations, and there was no clear pattern of geographic variation, with overlap of population variations in many morphological characters, although most of these studies were based on individuals from small numbers of populations. In addition, Hasumi and Iwasawa (1987a) suggested that environmental factors during developmental stages affected these variations.

In describing $H$. hidamontanus, Matsui (1987) studied phylogenetic relationships among seven Hynobius species, including $H$. lichenatus, using isozymes. The study resolved $H$. lichenatus to contain three major genetic groups whose

\footnotetext{
* Corresponding author. Tel. : : +81-75-753-6846; Fax : +81-75-753-6846; E-mail: fumi@zoo.zool.kyoto-u.ac.jp
}

doi:10.2108/zsj.30.167 distribution indicated a geographic structure. The study also revealed strong genetic differentiations between populations of this species, which suggest their distinct species status. Using Southern blotting, Kuro-o et al. (1992) studied phylogenetic relationships among eight Hynobius species, including $H$. lichenatus, and confirmed Matsui's (1987) results. In analyzing intraspecific genetic variation of $H$. tokyoensis using mitochondrial cytochrome b (Cytb) gene, Matsui et al. (2007) included $H$. lichenatus as an outgroup, and also ascertained results of the above two studies.

These studies suggested cryptic genetic diversity within $H$. lichenatus. However, because they did not focus on intraspecific variation of $H$. lichenatus, the studies suffered from limited geographical sampling with only a small number of individuals, leaving the necessity for more detailed surveys. To explore intraspecific variation in this species, we investigated its mtDNA genealogical structure throughout its distribution range. Recent molecular phylogenetic studies of Japanese small salamanders based on mtDNA analysis revealed cryptic diversity within species (e.g., Tominaga et al., 2006; Matsui et al., 2007; Yoshikawa et al., 2008), and estimated underlying evolutionary processes. Therefore, using mtDNA markers for $H$. lichenatus is expected to be effective for elucidating intraspecies cryptic diversity. Furthermore, $H$. lichenatus is the only amphibian species whose range is limited to northeastern Japan; the present study may therefore also be important to the understanding 
of amphibian biogeography in this region. The goals of this study are (1) to construct a robust intraspecific mtDNA genealogy, which will help infer population relationships and investigate cryptic diversity, and (2) to infer evolutionary history in $\mathrm{H}$. lichenatus.

\section{MATERIALS AND METHODS}

\section{Sampling}

A total of 215 samples including larvae and adults of $H$. lichenatus were collected from 75 localities throughout its distribution range (Fig. 1, Table 1). Based on phylogenetic relationships reported by Matsui et al. $(2007,2008)$, we chose two closely related species $H$. tokyoensis Tago, 1931 (AB266640) and $H$. nigrescens Stejneger, 1907 (AB548378) for comparison, and a more distantly related species $H$. retardatus Dunn, 1923 (AB363609) and Salamandrella keyserlingii Dybowski, 1870 (AB363573) as an outgroup for phylogenetic analysis.

\section{Sequencing}

Total genomic DNA was extracted from liver or muscle tissues frozen at $-80^{\circ} \mathrm{C}$ or preserved in $99 \%$ ethanol using standard phenol-chloroform extraction procedures (Hillis et al., 1996). The complete sequence of the mitochondrial Cytb gene was obtained using polymerase chain reaction (PCR) amplification with the primers described in Table 2. PCR amplification conditions included initial denaturation at $94^{\circ} \mathrm{C}$ for $4 \mathrm{~min}$, followed by 35 cycles at $94^{\circ} \mathrm{C}$ for $30 \mathrm{~s}, 52^{\circ} \mathrm{C}$ for $45 \mathrm{~s}$, and $72^{\circ} \mathrm{C}$ for $75 \mathrm{~s}$, and was completed by a final extension at $72^{\circ} \mathrm{C}$ for $7 \mathrm{~min}$. Amplified PCR products were electrophoresed on $2.0 \%$ agarose gel and viewed under UV light with ethidium bromide to check for correct fragment

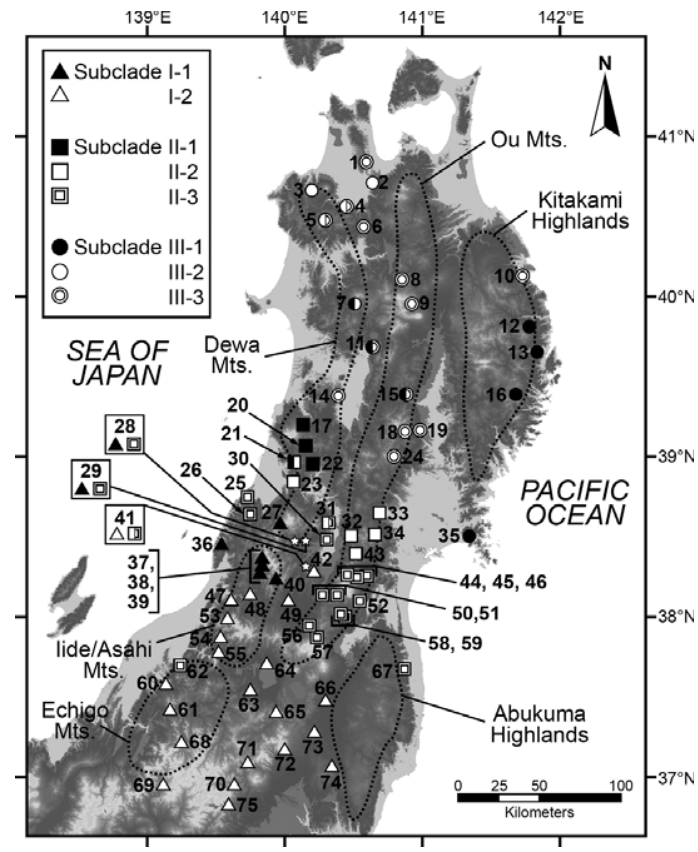

Fig. 1. Map of sampling localities of Hynobius lichenatus. Numbers correspond to the sampling point number given in Table 1. Labels indicate specific localities mentioned in the text. Map shading indicates topographic relief.
Table 1. Sampling locality, number of individuals $(n)$ and haplotypes $(H)$. Sampling point number corresponds to the sampling map labels in Fig. 1.

\begin{tabular}{|c|c|c|}
\hline $\begin{array}{l}\text { Sampling } \\
\text { Point }\end{array}$ & Sampling locality & $\mathrm{H}(n)$ \\
\hline 1 & Daishaka, Aomori-shi, Aomori Pref. & 5 h1, h2 (4) \\
\hline 2 & Namioka, Aomori-shi, Aomori Pref. & $3 \mathrm{~h} 3(3)$ \\
\hline 3 & Ajigasawa-machi, Nishitsugaru-gun, Aomori Pref. & 5 h4 (2), h5 (3) \\
\hline 4 & Tateko-yama, Hirosaki-shi, Aomori Pref. & $3 \mathrm{~h} 6, \mathrm{~h} 7(2)$ \\
\hline 5 & Nishimeya-mura, Nakatsugaru-gun, Aomori Pref. & $3 \mathrm{~h} 8, \mathrm{~h} 9, \mathrm{~h} 10$ \\
\hline 6 & Ikarisawa, Ikarigaseki, Hirakawa-shi, Aomori Pref. & 3 h11(2), h12 \\
\hline 7 & Moriyoshi, Kitaakita-shi, Akita Pref. & 6 h13, h14, h15 (2), h16, h17 \\
\hline 8 & Hachimantai, Kazuno-shi, Akita Pref. & $1 \mathrm{~h} 18$ \\
\hline 9 & Hachimantai, Hachimantai-shi, Iwate Pref. & 3 h11, h19, h20 \\
\hline 10 & Noda-mura, Kunohe-gun, Iwate Pref. & 2 h21, h22 \\
\hline 11 & Tazawa-ko, Senboku-shi, Akita Pref. & 3 h23, h24 (2) \\
\hline 12 & Iwaizumi-cho, Shimohei-gun, Iwate Pref. & 3 h25, h26, h27 \\
\hline 13 & Kebaraichi, Miyako-shi, Iwate Pref. & 3 h28 (2), h29 \\
\hline 14 & Omagari, Daisen-shi, Akita Pref. & 3 h30, h31 (2) \\
\hline 15 & Wakasennin, Kitakami-shi, Iwate Pref. & 2 h32, h33 \\
\hline 16 & Tsuchibuchi, Tono-shi, Iwate Pref. & 2 h27 (2) \\
\hline 17 & Chokai-san, Akita Pref. & 1 h34 \\
\hline 18 & Isawa-ku, Oshu-shi, Iwate Pref. & 4 h35 (2), h36, h37 \\
\hline 19 & Mizusawa, Oshu-shi, Iwate Pref. & 3 h35, h37, h38 \\
\hline 20 & Mamurogawa-machi, Mogami-gun, Yamagata Pref. & 1 h39 \\
\hline 21 & Tazawa-gawa, Sakata-shi, Yamagata Pref. & 5 h40, h41, h42 (2), h43 \\
\hline 22 & Sakegawa-mura, Mogami-gun, Yamagata Pref. & $1 \mathrm{~h} 44$ \\
\hline 23 & Kiyokawa, Sakata-shi, Yamagata Pref. & $1 \mathrm{~h} 45$ \\
\hline 24 & Kurikoma-yama, Ichinoseki-shi, Iwate Pref. & 2 h35 (2) \\
\hline 25 & Kamo, Tsuruoka-shi, Yamagata Pref. & $1 \mathrm{~h} 46$ \\
\hline 26 & Sakanoshita, Tsuruoka-shi, Yamagata Pref. & 2 h47, h48 \\
\hline 27 & Nishikawa-machi [1], Nishimurayama-gun, Yamagata Pref. & $3 \mathrm{~h} 49(3)$ \\
\hline 28 & Nishikawa-machi [2], Nishimurayama-gun, Yamagata Pref. & 8 h50, h51, h52 (2), h53, h49 (3) \\
\hline 29 & Nishikawa-machi [3], Nishimurayama-gun, Yamagata Pref. & 8 h49 (3), h53, h54, h55, h56, h57 \\
\hline 30 & Sanesawa-gawa, Sagae-shi, Yamagata Pref. & $1 \mathrm{~h} 58$ \\
\hline 31 & Tominami-gawa, Murayama-shi, Yamagata Pref. & 4 h59, h60, h61 (2) \\
\hline 32 & Shiramizu-gawa, Higashine-shi, Yamagata Pref. & 5 h62, h63(4) \\
\hline 33 & Kami-machi, Kami-gun, Miyagi Pref. & $3 \mathrm{~h} 64, \mathrm{~h} 65, \mathrm{~h} 66$ \\
\hline 34 & Taiwa-cho, Kurokawa-gun, Miyagi Pref. & $3 \mathrm{~h} 67, \mathrm{~h} 68, \mathrm{~h} 69$ \\
\hline 35 & Mano, Ishinomaki-shi, Miyagi Pref. & 3 h27(3) \\
\hline 36 & Sasagawa, Murakami-shi, Niigata Pref. & 6 h70(4), h71, h72 \\
\hline 37 & Miomote-gawa [1], Murakami-shi, Niigata Pref. & 4 h73, h74, h75, h76 \\
\hline 38 & Miomote-gawa [2], Murakami-shi, Niigata Pref. & $1 \mathrm{~h} 77$ \\
\hline 39 & Miomote-gawa [3], Murakami-shi, Niigata Pref. & $1 \mathrm{~h} 78$ \\
\hline 40 & Oguni-machi, Nishiokitama-gun, Yamagata Pref. & $3 \mathrm{~h} 79, \mathrm{~h} 80, \mathrm{~h} 81$ \\
\hline 41 & \multicolumn{2}{|c|}{ Yamanobe-machi [1], Higashimurayama-gun, Yamagata Pref. 8 h82 (5), h52 (2), h83 } \\
\hline 42 & \multicolumn{2}{|c|}{ Yamanobe-machi [2], Higashimurayama-gun, Yamagata Pref. 4 h84 (4) } \\
\hline 43 & Omoshiro-yama, Yamagata-shi, Yamagata Pref. & 3 h63 (3) \\
\hline 44 & Fudo-sawa, Yamagata-shi, Yamagata Pref. & 2 h52, h85 \\
\hline 45 & Zao-dam, Yamagata-shi, Yamagata Pref. & $1 \mathrm{~h} 58$ \\
\hline 46 & Kawasaki-machi, Shibata-gun, Miyagi Pref. & 3 h52, h55, h86 \\
\hline 47 & Torisaka-yama, Tainai-shi, Niigata Pref. & $1 \mathrm{~h} 87$ \\
\hline 48 & Sekikawa-mura, Iwafune-gun, Niigata Pref. & $1 \mathrm{~h} 88$ \\
\hline 49 & Nagai-shi, Yamagata Pref. & 3 h89, h90, h91 \\
\hline 50 & Oishida-yama, Kaminoyama-shi, Yamagata Pref. & $1 \mathrm{~h} 92$ \\
\hline 51 & Zao-kogen, Kaminoyama-shi, Yamagata Pref. & 2 h52, h93 \\
\hline 52 & Shichikashuku-machi, Katta-gun, Miyagi Pref. & 2 h52, h94 \\
\hline 53 & Shimosanko, Shibata-shi, Niigata Pref. & 3 h95, h96, h97 \\
\hline 54 & Gozu, Agano-shi, Niigata Pref. & 4 h95, h98 (2), h99 \\
\hline 55 & Aga-machi, Higashikanbara-gun, Niigata Pref. & 1 h100 \\
\hline 56 & Sekine, Yonezawa-shi, Yamagata Pref. & 5 h101, h102, h103, h104, h105 \\
\hline 57 & Touge, Yonezawa-shi, Yamagata Pref. & 5 h102 (2), h106 (3) \\
\hline 58 & lizaka-machi [1], Fukushima-shi, Fukushima Pref. & 2 h52, h107 \\
\hline 59 & lizaka-machi [2], Fukushima-shi, Fukushima Pref. & $1 \mathrm{~h} 52$ \\
\hline 60 & Shitada, Sanjyo-shi, Niigata Pref. & 3 h108, h109 (2) \\
\hline 61 & Irihirose, Uonuma-shi, Niigata Pref. & 1 h109 \\
\hline 62 & Kamiotani, Kamo-shi, Niigata Pref. & $1 \mathrm{~h} 110$ \\
\hline 63 & Showa-mura, Onuma-gun, Fukushima Pref. & 3 h111 (3) \\
\hline 64 & Yamato-machi, Kitakata-shi, Fukushima Pref. & 3 h112 (2), h113 \\
\hline 65 & Shimogo-machi, Minamiaizu-gun, Fukushima Pref. & $1 \mathrm{~h} 114$ \\
\hline 66 & Ouse-machi, Koriyama-shi, Fukushima Pref. & $2 \mathrm{~h} 115(2)$ \\
\hline 67 & Haramachi-ku, Minamisoma-shi, Fukushima Pref. & 3 h116, h117, h118 \\
\hline 68 & Ginzandaira, Uonuma-shi, Niigata Pref. & $1 \mathrm{~h} 119$ \\
\hline 69 & Minakami-machi, Tone-gun, Gunma Pref. & 4 h119 (2), h120 (2) \\
\hline 70 & Nikko-shi (former Kuriyama-mura), Tochigi Pref. & 3 h111 (3) \\
\hline 71 & Nakamiyori, Nikko-shi, Tochigi Pref. & 3 h121 (3) \\
\hline 72 & Nasushiobara-shi, Tochigi Pref. & 4 h111 (2), h122, h123 \\
\hline 73 & Shirakawa-shi (former Tashiro-mura), Fukushima Pref. & 3 h115 (2), h124 \\
\hline 74 & Tanagura-machi, Higashishirakawa-gun, Fukushima Pref. & 3 h111, h125 (2) \\
\hline 75 & Nikko-shi, Tochigi Pref. & $1 \mathrm{~h} 126$ \\
\hline $\begin{array}{l}\text { Hynobius } \\
\text { tokyoensis }\end{array}$ & Hachioji-shi, Tokyo met. govern. & $1 \mathrm{AB} 266640$ \\
\hline H. nigrescens & Kami-machi, Kami-gun, Miyagi Pref. & 1 AB548378 \\
\hline H. retardatus & Ebetsu-shi, Hokkaido Pref. & 1 AB363609 \\
\hline $\begin{array}{l}\text { Salamandrella } \\
\text { keyserlingii }\end{array}$ & Kushiro-shi, Hokkaido Pref. & $1 \mathrm{AB} 363573$ \\
\hline
\end{tabular}


Table 2. List of primers used in this study.

\begin{tabular}{llll}
\hline \multicolumn{1}{c}{ Primer name } & \multicolumn{1}{c}{ Sequence $\left(5^{\prime}\right.$ to $\left.3^{\prime}\right)$} & \multicolumn{1}{c}{ Position } & \multicolumn{1}{c}{ Source } \\
\hline HYD_Cytb_F1 & CYAAYCCTAAAGCWGCAAAATA & external forward & Matsui et al. (2008) \\
cytb_R1_cynops & AARTAYGGGTGRAADGRRAYTTTRTCT & internal reverse & This study \\
cytb_F2_cynops & CAYTTYYTGYTMCCATTYYTAATTGCAGG & internal forward & This study \\
salamander_cytb_R_N2 & YTYTCAATCTTKGGYTTACAAGACC & external reverse & Matsui et al. (2008) \\
\hline
\end{tabular}

Rambaut, 2007). As no known calibration points exist, we used two different rates of hynobiids mitochondrial DNA evolution: Weisrock et al.'s (2001) rate of $1.28 \%$ sequence divergence per MY ( $0.64 \%$ per MY per lineage: Calibration I) and Yoshikawa et al.'s (2008) rate of $1.36 \%$ per MY $(0.68 \%$ per MY per lin-

size. PCR products were subsequently purified using $13 \%$ polyethylene glycol (PEG) purification procedures. Cycle sequencing reactions of purified PCR products were performed with $\mathrm{ABI}$ Prism BigDye Terminator Ver. 3.1 Cycle Sequencing Kit (Applied Biosystems), in both directions with the same primers as used for PCR amplification. Cycle sequencing reaction products were cleaned by ethanol precipitation following manufacturer's protocol and these cleaned products were analyzed with an ABI Prism 3130 Genetic Analyzer (Applied Biosystems). Continuous gene sequences were assembled and edited manually using Chromas Pro version 1.34 (Technelysium Pty Ltd., Tewantin, Australia) and aligned using CLUSTALX2 version 2.1 (Larkin et al., 2007). All generated sequences have been deposited in GenBank under the accession numbers AB266669-AB266671 and AB750781-AB750992.

\section{Phylogenetic analysis}

We performed maximum likelihood (ML) and Bayesian inference (BI) analyses to estimate phylogenetic relationships. ML trees were generated with Treefinder ver. March 2011 (Jobb, 2011). The best-fit substitution models were determined for individual codon positions with Kakusan4 (Tanabe, 2011), using the Akaike Information Criterion (AIC) (Akaike, 1974). Nodal support was estimated with 1000 bootstrap replicates and nodes were considered to be strongly supported if they had bootstrap values (BS) of $70 \%$ or greater (Huelsenbeck and Hillis, 1993). BI trees were generated with MrBayes 3.1.2 (Ronquist and Huelsenbeck, 2003). The best-fit substitution models were determined with Kakusan4 (Tanabe, 2011), using the Bayesian Information Criterion (BIC) (Schwarz, 1978). BI analyses were performed using three heated and one cold Metropolis coupled Markov Chain Monte Carlo (MCMC) for 10 million generations, sampling every 100 generations. Suitable burn-in and convergence of parameters were determined using Tracer ver. 1.5 (Rambaut and Drummond, 2009). Although all samples showed convergence after 800,000 generations, we conservatively discarded the first $15 \%$ of trees (1.5 million generations) as burn-in. After burn-in, trees of two independent runs were combined in a single majority consensus topology, and we considered nodes to be strongly supported if they had Bayesian posterior probabilities (BPP) values $95 \%$ or greater (Leaché and Reeder, 2002). Based on clades identified from the phylogenetic tree, we calculated the genetic distances (uncorrected pairwise distances) between clades using MEGA 5.05 (Tamura et al., 2011).

\section{Population analysis}

Using the main clades and subclades identified from the phylogenetic tree, population statistics were performed using ARLEQUIN ver. 3.5.1.3 (Excoffier and Lischer, 2010). Genetic diversity within main clades and subclades was measured by haplotype diversity ( $h$; Nei, 1987) and nucleotide diversity ( $\pi$; Nei and Tajima, 1981). To examine deviations from neutrality, Tajima's $D$ (Tajima, 1989) and Fu's $F_{S}(F u, 1997)$ neutrality tests were performed. The significance of both neutrality tests was examined with 10,000 replicates.

\section{Divergence time estimation}

For divergence time estimation, we selected 16 Cytb sequences from the $\mathrm{H}$. lichenatus datasets that represent each clade and subclade on the phylogenetic tree. We also added four other species used in the phylogenetic analysis. To estimate divergence times, we used Bayesian method using BEAST ver. 1.6.2 (Drummond and eage: Calibration II). BEAST analyses were performed using the relaxed uncorrelated lognormal molecular clock (Drummond et al., 2006), under a HKY + G model of sequence evolution, and the best topology obtained from the $\mathrm{Bl}$ analyses was used as a starting tree. We used default prior distributions for all other parameters and ran the analyses for 20 million generations, sampling every 1000 generations. Suitable burn-in and convergence of parameters were determined using Tracer ver. 1.5 (Rambaut and Drummond, 2009), and the first 3 million generations were discarded as burn-in.

\section{RESULTS}

\section{Phylogenetic analysis}

The total alignment for the complete Cytb gene sequence (1141 base pairs) yielded 126 haplotypes, 300 variable sites, and 240 parsimony informative sites. Private haplotypes dominate the Cytb gene dataset, with 111 of the 126 haplotypes corresponding to one locality.

For $\mathrm{ML}$ and $\mathrm{BI}$ analyses, the best-fit model of sequence evolution was determined for individual codon positions (1st, 2nd and 3rd). This yielded GTR + G (1st), J2 + G (2nd) and $\mathrm{J} 3+\mathrm{G}$ (3rd) for ML analysis, and SYM + G (1st), HKY85 + $\mathrm{G}$ (2nd) and $\mathrm{J} 3+\mathrm{G}$ (3rd) for $\mathrm{BI}$ analysis. The $\mathrm{ML}$ and $\mathrm{BI}$ trees (Figs. 2 and 3 ) had similar topologies, and strongly indicated the monophyly of $H$. lichenatus by high support values $(B S=97$ and $B P P=100)$. However, relationships between $H$. lichenatus and two closely related species $(H$. tokyoensis and $H$. nigrescens) were unresolved due to low support values.

Within $\mathrm{H}$. lichenatus, three main clades (Clade I, II, and III), each with several subclades, were recognized (Figs. 2 and 3). All clades and subclades were strongly supported by high BS and BPP. Clade I consists of northern Kanto populations, Clade II of southern Tohoku populations, and Clade III of northern Tohoku population samples (Fig 1). The ML and $\mathrm{BI}$ trees indicated deep phylogeographic structure among these main clades that showed allopatric/parapatric distribution except at localities 28, 29, and 41 (Fig. 1). At these localities, haplotypes of Clades I and II were shared sympatrically. The mean pairwise genetic distances were $7.9 \%$ (range $=7.2-8.5 \%$ ) between Clades I and II, $7.4 \%$ (6.8-8.0\%) between Clades I and III, and 6.4\% (5.8-6.9\%) between Clades II and III.

Clade I includes two allopatric subclades (Subclade I-1 and I-2) that have a mean pairwise genetic distance of $3.2 \%$ (range $=2.8-3.6 \%$ ). Clade II includes three subclades (II-1, II-2, and II-3); however, the relationship between these subclades is unresolved due to low support values. Haplotypes belonging to two of these three subclades co-occurred at localities 21, 31, and 41. The mean pairwise genetic distances were $2.1 \%$ (range $=1.7-2.4 \%$ ) between Subclades $\mathrm{II}-1$ and II-2, $4.2 \%$ (range $=3.7-4.7 \%$ ) between Subclades $\mathrm{II}-1$ and $\mathrm{II}-3$, and $3.7 \%$ (range = 3.2-4.1\%) between Subclades II-2 and II-3. Clade III includes three subclades (III-1, III-2, and III-3) whose relationships are unresolved. 


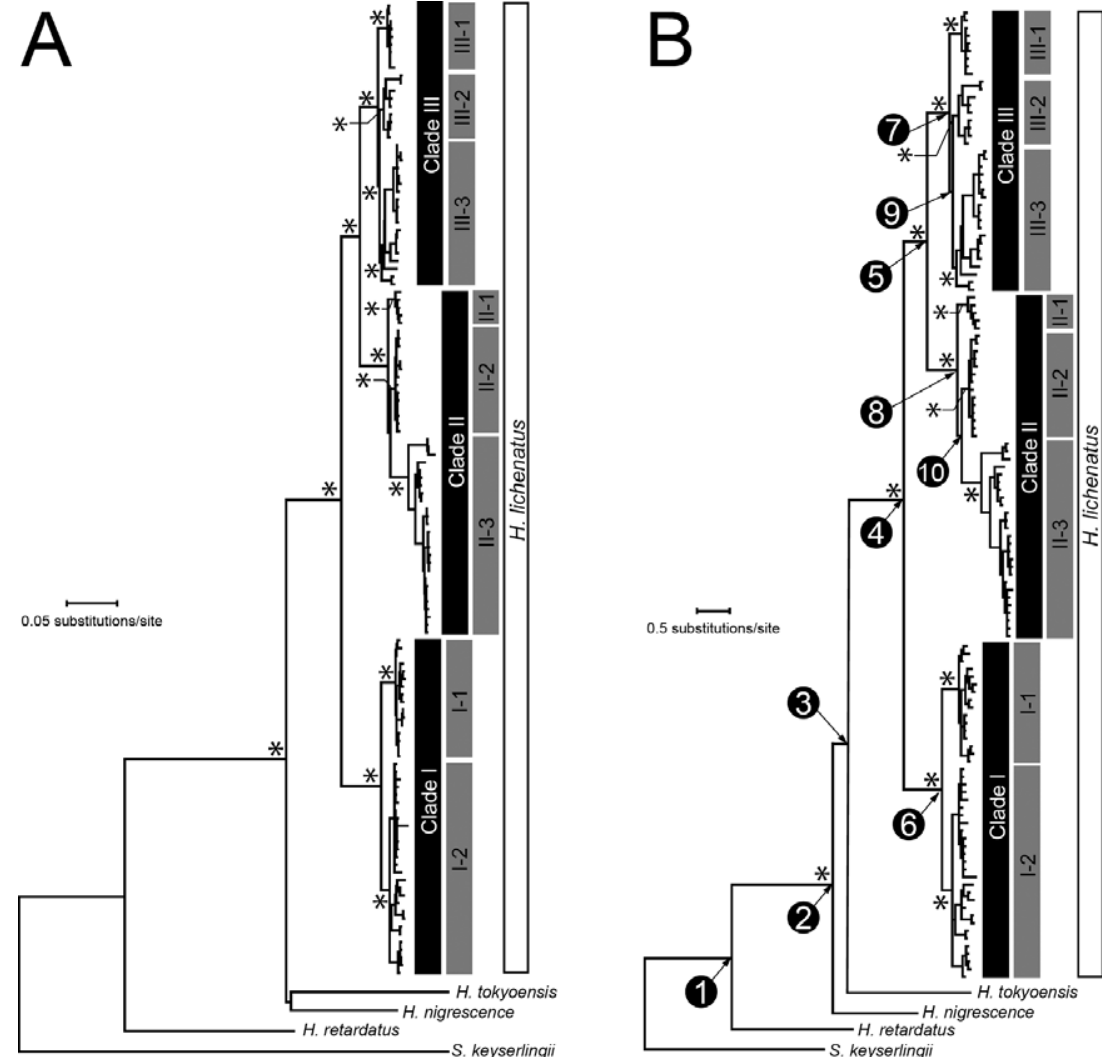

Fig. 2. Phylogenetic trees of Hynobius lichenatus from (A) maximum likelihood (ML) and (B) Bayesian inference $(\mathrm{BI})$ methods. Asterisks on the branches indicate maximum likelihood bootstrap value (only values $>70 \%$ are shown) and Bayesian posterior probability (only values $>95 \%$ are shown). Node numbers in black circles indicate divergence splits from BEAST analysis (Table 4). The clades and subclades correspond to those shown in Fig. 1.
A

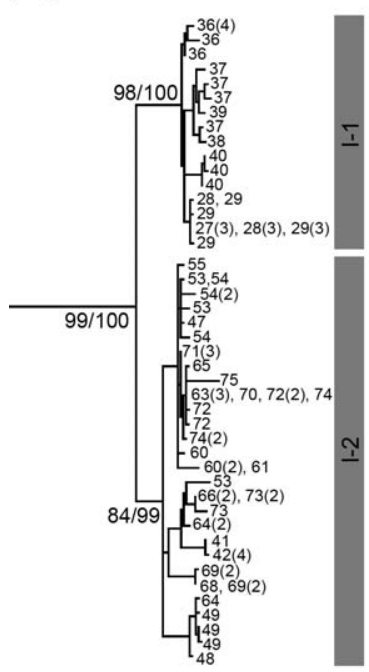

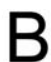

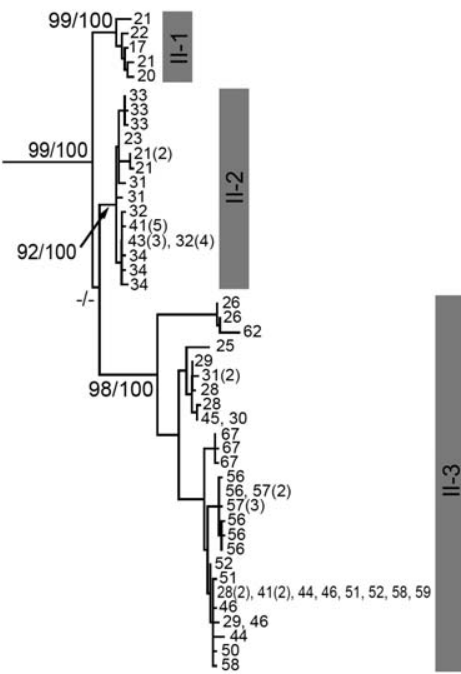

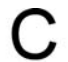

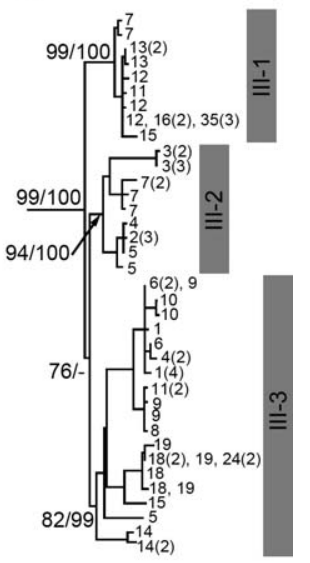

$\overparen{0.05 \text { substitutions/site }}$

Fig. 3. Phylogenetic relationships within the major clades of Hynobius lichenatus identified in Fig. 2: (A) Clade I, (B) Clade II and (C) Clade III. Tree topology and branch lengths are based on ML tree. Numbers on the branches indicate ML bootstrap value (left, only values $\geq 70 \%$ are shown) and $\mathrm{BI}$ posterior probability (right, only values $\geq 95 \%$ are shown). Tip labels are sampling localities and number of individuals (see Fig. 1, Table 1). The clades and subclades correspond to those shown in Fig. 1.

Haplotypes belonging to two of these three subclades coexisted at localities 4, 5, 7, 11, and 15 . The mean pairwise genetic distances were $2.7 \%$ (range $=2.3$ $3.0 \%$ ) between Subclades III-1 and III-2, 2.4\% (range $=2.1-2.7 \%$ ) between Subclades III-1 and III-3, and $2.7 \%$ (range $=2.4-3.1 \%$ ) between Subclades III-2 and III-3.

\section{Population analysis}

Measures of genetic diversity are shown in Table 3. Overall, the data showed high haplotype and nucleotide diversities for each of the main clades and subclades. In Clade I, Subclade I-1 had genetic diversity lower than Subclade I-2. In Clade II, Subclade II-2 had the lowest genetic diversity among the three subclades, and in Clade III, Subclade III-1 had the lowest diversity among the three subclades recognized. Results of the neutrality test were not significant for all main clades and subclades, except for Subclades II-2 and III-1 (Table 3). Subclade II-2 showed a significant value for Fu's $F_{\mathrm{S}}$, but Tajima's $D$ value was not significant. Subclade III-1 showed significant value for both neutrality tests.

\section{Divergence time}

Molecular dating indicated that $H$. lichenatus diverged between the middle Miocene and early Pleistocene. The divergence between $H$. lichenatus and two closely related species $(H$. tokyoensis and $H$. nigrescens) occurred at roughly 17-18 million years before present (MYBP), although the estimates of each node were wide in range with substantial overlaps between the 95\% credibility intervals (Table 4). Within $H$. lichenatus, the divergence between Clade I and the ancestor of Clades II and III occurred at approximately 8.72 or 9.28 MYBP using the Calibration II and Calibration I, respectively. Subsequently, the divergence between Clades II and III occurred at approximately 6.55-6.98 MYBP. Within each clade, Clade I split into two subclades at approximately 2.70-2.87 MYBP, Clade II into three subclades at approxi- 
Table 3. Genetic diversity indices and results of neutrality tests. Number of individuals $(n)$, number of haplotypes $(\mathrm{Hn})$, haplotype diversity $(h)$ and its standard deviation (SD), nucleotide diversity $(\pi)$ and its SD, Tajima's $D$, and Fu's Fs (significance denoted by asterisks; ${ }^{*}$ denotes $<0.05$ and ${ }^{* *}$ denotes $\left.<0.02\right)$.

\begin{tabular}{crrcccc}
\hline $\begin{array}{c}\text { Clades and } \\
\text { Subclades }\end{array}$ & $n$ & $\mathrm{Hn}$ & $h \pm \mathrm{SD}$ & $\pi \pm \mathrm{SD}$ & Tajima's $D$ & Fu's FS \\
\hline Clade I & 81 & 44 & $0.9676 \pm 0.0091$ & $0.020492 \pm 0.010091$ & -0.53889 & -3.69557 \\
Subclade I-1 & 28 & 16 & $0.8862 \pm 0.0502$ & $0.006427 \pm 0.003451$ & -1.06847 & -2.62276 \\
Subclade I-2 & 53 & 28 & $0.9550 \pm 0.0156$ & $0.013074 \pm 0.006592$ & -0.95801 & -2.34841 \\
Clade II & 72 & 45 & $0.9664 \pm 0.0114$ & $0.023954 \pm 0.011763$ & 0.11985 & -4.42136 \\
Subclade II-1 & 5 & 5 & $1.0000 \pm 0.1265$ & $0.005960 \pm 0.003954$ & -0.84004 & -0.87453 \\
Subclade II-2 & 25 & 14 & $0.8933 \pm 0.0456$ & $0.003512 \pm 0.002023$ & -1.01535 & $-4.67632^{\star *}$ \\
Subclade II-3 & 42 & 26 & $0.9373 \pm 0.0282$ & $0.012143 \pm 0.006176$ & -0.88558 & -3.63898 \\
Clade III & 62 & 37 & $0.9751 \pm 0.0082$ & $0.023135 \pm 0.011398$ & -0.02878 & -1.97418 \\
Subclade III-1 & 15 & 9 & $0.8476 \pm 0.0878$ & $0.002571 \pm 0.001599$ & $-1.77339^{\star}$ & $-2.90203^{\star}$ \\
Subclade III-2 & 15 & 9 & $0.9238 \pm 0.0440$ & $0.014240 \pm 0.007543$ & 1.23287 & 2.47648 \\
Subclade III-3 & 32 & 19 & $0.9536 \pm 0.0200$ & $0.016541 \pm 0.008370$ & 0.05031 & 0.33778 \\
\hline
\end{tabular}

genes, Matsui et al. (2007) recognized two clades ( $A$ and $B$, with recognizable subclades only in $\mathrm{B}$ ) in $H$. tokyoensis. When their original data were recalculated for only Cytb gene, a mean $( \pm \mathrm{SE})$ pairwise distance of $5.7 \pm 0.6 \%$ was obtained between the two clades. Similar recalculation resulted in means of the pairwise distances between $H$. lichenatus and $H$. nebulosus $+H$. tokyoensis at 12.9 $\pm 0.7 \%$, and between $H$. tokyoensis and H. nebulosus at $11.3 \pm 0.8 \%$. This limited information indicates the level of differentiation between the three clades of $H$. lichenatus to be slightly smaller than that between different species of Hynobius, but larger than that found

Table 4. Estimates of divergence time. Nodes correspond to the 10 labeled nodes on the BI tree in Fig. 2B. Calibrations I and II used $1.28 \%$ and $1.36 \%$ sequence divergences per MY, respectively.

\begin{tabular}{crrrrrrrr}
\hline & \multicolumn{3}{c}{ Calibration I } & & \multicolumn{3}{c}{ Calibration II } \\
\cline { 2 - 5 } \cline { 6 - 8 } Node & Mean & 95\% lower & $95 \%$ upper & & Mean & 95\% lower & $95 \%$ upper \\
\hline 1 & 37.2768 & 25.3108 & 51.5221 & & 35.0050 & 23.6580 & 48.0781 \\
2 & 18.2679 & 12.9047 & 23.7284 & & 17.1294 & 12.3492 & 22.3791 \\
3 & 17.8186 & 12.5328 & 23.3777 & & 16.6852 & 11.7030 & 21.6846 \\
4 & 9.2801 & 6.7988 & 12.0432 & & 8.7218 & 6.4860 & 11.2687 \\
5 & 6.9810 & 5.0517 & 8.9381 & & 6.5548 & 4.8849 & 8.4579 \\
6 & 2.8738 & 1.6927 & 4.1476 & & 2.7098 & 1.6408 & 3.9537 \\
7 & 2.8648 & 1.9928 & 3.8521 & & 2.6871 & 1.8731 & 3.5620 \\
8 & 3.6297 & 2.5284 & 4.8294 & & 3.4180 & 2.3835 & 4.5477 \\
9 & 2.6767 & 1.8639 & 3.6215 & & 2.5100 & 1.7154 & 3.3226 \\
10 & 3.6255 & 2.5188 & 4.8265 & & 3.4139 & 2.3835 & 4.5507 \\
\hline
\end{tabular}

mately 3.41-3.62 MYBP, and Clade III into three subclades at approximately 2.51-2.86 MYBP (Table 4).

\section{DISCUSSION}

\section{Phylogeny and genetic structure}

The level of mtDNA Cytb genetic differentiation and structure found in $\mathrm{H}$. lichenatus reveal the presence of three deeply divergent clades that show a general geographical congruence with three regions of northeastern Japan. The relationships among these three main clades are fully resolved with high support, although the relationships between subclades in Clades II and III could not be resolved with sufficient support. The observed geographic structure of these three main clades slightly differs from those reported previously using nuclear DNA (nDNA) markers (Matsui, 1987; Kuro-o et al., 1992). In these studies, the northern Tohoku clade, corresponding to Clade III in this study ,splits first, unlike our result in which Clade I (northern Kanto clade) splits first from the remaining two clades (Figs. 2 and 3). This discordance may be ascribable to different divergence patterns between mitochondrial and nDNA markers.

Uncorrected pairwise distances found among three major clades were about $7 \%$ in $\mathrm{H}$. lichenatus. Matsui et al. (2007) pointed out that few sequence diversity data were available for species of Hynobius. This situation still holds and direct comparison of the present results of $H$. lichenatus with the other species in terms of the genes sequenced is not easy. From analyses of Cytb gene and control region between two clades in $H$. tokyoensis. Genetic distances among subclades within each major clade (about 2-4\%) were larger than those obtained for $H$. tokyoensis (about $0.9-1.7 \%$ for Clade B in Matsui et al. [2007]). This high genetic diversity suggests the possibility of the presence of cryptic species within $H$. lichenatus.

Larval individuals carrying haplotypes from Clades I and II were found to coexist at three localities $(28,29$, and 41 in Fig 1). Unfortunately, adult individuals were not obtained in these localities, and future analyses using nuclear markers would reveal whether or not hybridization occurs between the two clades.

At the clade level, both haplotype and nucleotide diversities were high in $H$. lichenatus. However, degree of divergence differed among clades. Among subclades in Clade I, Subclades I-1 and I-2, with insignificant results in the neutrality test, seem to have long-stable genetic structures. Likewise, Subclades II-1 and II-3, exhibiting insignificant results in neutrality test, seem to have the structures like subclades in Clade I. In contrast, Subclade II-2, which occupies the northernmost range of Clade II, and showing significant Fu's Fs value, seems a tendency of recent population expansion. Among subclades of Clade III, Subclade III-1, occurring easternmost region of the clade, and showing significant value for both neutrality tests, is thought to clearly indicate a recent population expansion. In contrast, Subclades III-2 and III-3, with insignificant Fu's Fs or Tajima's $D$ seem to have long-stable genetic structures. Overall, genetic diversity indices show high values and results of neutrality tests show significant negative values, except for some subclades in $\mathrm{H}$. lichenatus. These results indicate long-term stability of demographic structure in this species.

\section{Divergence time and historical biogeography}

Northeastern Honshu, where $H$. lichenatus occurs, was under the sea except for the current Kitakami and Abukuma Highlands (Sato, 1994; Suzuki, 1989; Yamaji and Sato, 1989) before 15 and 12 MYBP in the middle Miocene, when land formation through volcanic activities began (Koike et al., 2005). The ancestral stock of $H$. lichenatus, probably confined to southwestern Japan, would have migrated northward during these periods. Our estimation suggested the divergence of this species from its sister species occurred in these ages, and huge volcanic activities may have induced 


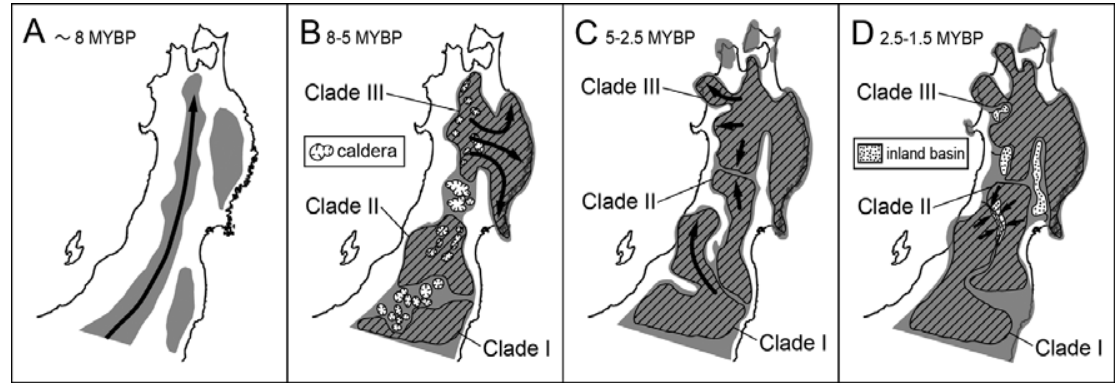

Fig. 4. Paleogeographic map of northeastern Japan, showing estimated dispersal (bold arrow) and estimated distribution (shaded zone) of each clade of Hynobius lichenatus. Gray zones indicate estimated land areas. (A) is based on Koike et al. (2005), (B) is modified from Sato (1994), and (C) and (D) are based on Koike et al. (2005), Machida et al. (2006), and Nagasawa (1997).

vicariance of the ancestral lineages.

Around 8 MYBP in the late Miocene, most of the current regions of the Ou Mountains started to uplift and became land (Koike et al., 2005; Fig. 4A), and ancestral $H$. lichenatus seems to have expanded its range there. However, regions other than the current Ou Mountains were still under the sea during this period, and the Kitakami/Abukuma Highlands were isolated islets. Therefore, range expansion of ancestral $H$. lichenatus would have been confined to regions around the Ou Mountains. It was estimated that divergence of Clade I and the others occurred around 9 MYBP, and Clades II and III diverged around 7 MYBP. The presence of huge calderas at the northern edge and central part of the Ou Mountains is suggested at 8-3.5 MYBP (Sato, 1994; Fig. 4B), and these calderas are close to the boundary of Clades I and II, and of Clades II and III, respectively. These regions were narrowed through introgression of the sea in this period, and volcanic activities in such narrow land regions may have caused vicariance of habitats and genetic differentiation among the three clades. By 5 to 4 MYBP in the early Pliocene, the Ou Mountains and the Kitakami Highlands were connected by land, where Clade III began invasion (Fig. 4B).

Around 3-2.5 MYBP, the orogenesis of the DewaEchigo Mountains began (Nagasawa, 1997; Machida et al., 2005). Clade I seems to have expanded its range from the southern Ou Mountains to the Echigo-lide/Asahi Mountains, and Clade II from the central Ou Mountains to the Dewa Mountains. However, the region between the lide/Asahi and the Dewa mountains remained undersea (Amano and Sato, 1989; Nagasawa, 1997), which would have prohibited connection of the two clades (Fig. 4C). Active uplifts in the Dewa-Echigo Mountains in this period would have promoted genetic differentiations within Clades I and II.

Thereafter, uplift in each of the mountains proceeded along with the marine recession, followed by formation of inland basins with marshy areas among mountains and expansion of lands (Suzuki, 1989; Koike et al., 2005: Fig. 4D). Deposition in inland basins widened land areas where each clade seems to have expanded its distribution range. Clades I and II would have secondarily contacted in this region, resulting in sympatric distribution of the two clades as seen in the sampling sites 28,29 , and 41 by the late Pliocene, until which age the deposition in inland basins continued (Suzuki, 1989).
In this way, diversification of $H$. lichenatus is thought to have been shaped by geohistorical events, such as orogenesis, sea level changes, and volcanic activity, within northeastern Honshu from the late Miocene to the early Pleistocene. Previous studies on genetic variation of animals occurring in northeastern Japan (e.g., Apodemus field mice [Suzuki et al., 2004]; Salvelinus trouts [Yamamoto et al., 2004]; Carabus ground beetles [Sota et al., 2001]) indicate much younger ages of differentiations than in $H$. lichenatus, mostly during the mid Pliocene and the last glacial ages, although older differentiation ages are estimated in freshwater fishes such as Oryzias Medaka (4.7 MYBP: Takehana et al., 2003) and Lefua loaches (2 MYBP: Mihara et al., 2005). Similarly, recent phylogenetic studies of Japanese clawed salamander (Onychodactylus japonicus [Houttuyn, 1782] indicate its very old differentiation in northeastern Honshu (Yoshikawa et al., 2008, 2012).

For these reasons, $\mathrm{H}$. lichenatus and $\mathrm{O}$. japonicus are thought to represent comparatively ancient faunal elements in this region, unlike many other animal species. This suggest that amphibians are important faunal elements in considering zoogeography and geohistory of northeastern Japan. Unfortunately, geohistrical knowledge from the mid-Miocene to Pliocene in this region is still meager, and as it is difficult to discuss the zoogeography of those ages, future intensive studies in the field of geology are urgently required.

\section{ACKNOWLEDGEMENTS}

We thank T. Abe, K. Araya, K. B. Dontchev, H. Fujita, M. Hayashi, S. Ikeda, Y. Inoue-Watanabe, the late H. Iwasawa, M. Kakegawa, M. Kuro-o, N. Maeda, J. Marunouchi, Y. Misawa, S. Mori, M. Nagano, T. Sawahata, T. Sugahara, T. Sugihara, T. Sugiki, S. Tanabe, A. Tominaga, R. Ueshima, M. Yamagami, N. Yoshikawa, and the late E. Yoshimura for help in collecting specimens, and $\mathrm{H}$. Tamate for providing specimens. We thank K. Eto, $\mathrm{N}$. Kuraishi, T. Matsuki, T. Shimada, A. Tominaga, and N. Yoshikawa for assisting with experiments and invaluable advice on analytic techniques. Two anonymous reviewers provided valuable comments on the manuscript. This study was partially supported financially by grants from The Monbukagakusho through the Japanese Society for the Promotion of Sciences (JSPS: 11640697, 20510215, 23510294) to MM and Showa Seitoku Memorial Foundation to KN.

\section{REFERENCES}

Akaike H (1974) New look at statistical-model identification. IEEE Trans Auto Contr 19: 716-723

Amano K, Sato H (1989) Neogene tectonics of the central part of Northeast Honshu Arc. Mem Geol Soc Jpn 32: 81-96

Aoki R (1977) On the fifth toe in Hynobius. Ryoseirui-Hachurui Kenkyu Kaishi 9: 13-14

Drummond AJ, Rambaut A (2007) BEAST: Bayesian evolutionary analysis by sampling trees. BMC Evol Biol 7: 214

Drummond AJ, Ho SYW, Phillips M, Rambaut A (2006) Relaxed phylogenetics and dating with confidence. PLoS Biol 4: 699-710

Excoffier L, Lischer HEL (2010) Arlequin suite ver 3.5: A new series of programs to perform population genetics analyses under Linux and Windows. Mol Ecol Res 10: 564-567

Fu YX (1997) Statistical tests of neutrality of mutations against population growth, hitchhiking and background selection. Genetics 
147: 915-925

Hasumi M, Iwasawa $\mathrm{H}$ (1987a) Geographic variation in the tail of the Japanese salamander, Hynobius lichenatus, with special reference to taxonomic bearing. Zool Sci 4: 159-166

Hasumi M, Iwasawa H (1987b) Geographic variation in morphorogical characters of the Japanese salamander, Hynobius lichenatus. Sci Rep Niigata Univ D Biol 24: 15-30

Hasumi M, Iwasawa $H$ (1988) Geographic variation in the number of teeth of the Japanese salamander, Hynobius lichenatus. Sci Rep Niigata Univ D Biol 25: 1-17

Hasumi M, Iwasawa H (1993) Geographic variation in the pes of the salamander Hynobius lichenatus: a comparison with tetradactyl Hynobius hidamontanus and pentadactyl Hynobius nigrescens. Zool Sci 10: 1017-1027

Hillis DM, Moritz C, Mable BK (1996) Molecular Systematics. 2nd ed, Sinaeur Assoc, Sunderland, Massachusetts

Huelsenbeck JP, Hillis DM (1993) Success of phylogenetic methods in the four-taxon case. Syst Biol 42: 247-264

Inukai T, Makino S (1933) On a local variation of Hynobius lichenatus Boulenger found in Akita-ken and Yamagata-ken. Rep Jap Assoc Ad Sci 8: 454-457

Jobb G (2011) TREEFINDER version of March 2011. Munich, Germany. Distributed by the author at www.treefinder.de

Koike K, Tamura T, Chinzei K, Miyagi T (Eds.) (2005) Regional Geomorphology of the Japanese Islands, Vol. 3, Geomorphology of Tohoku Region. University of Tokyo Press, Tokyo

Kuro-o M, Hikida T, Kohno S-I (1992) Molecular genetic analysis of phylogenetic relationships in the genus Hynobius by means of Southern blot hybridization. Genome 35: 478-491

Larkin MA, Blackshields G, Brown NP, Chenna R, McGettigan PA, McWilliam $\mathrm{H}$, et al. (2007) Clustal W and Clustal X version 2.0 Bioinformatics 23: 2947-2948

Leaché AD, Reeder TW (2002) Molecular systematics of the eastern fence lizard (Sceloporus undulatus): a comparison of parsimony, likelihood, and Bayesian approaches. Syst Biol 51: $44-68$

Machida H, Matsuda T, Umitsu M, Koizumi T (Eds.) (2005) Regional Geomorphology of the Japanese Islands, Vol. 5, Geomorphology of Chubu Region. University of Tokyo Press, Tokyo

Maruyama T (1977) Digital variation in the hind legs of the salamander Hynobius lichenatus. Jpn J Herpetol 7: 10-14

Matsui M (1987) Isozyme variation in salamanders of the nebulosuslichenatus complex of the genus Hynobius from eastern Honshu, Japan, with a description of a new species. Jpn J Herpetol 12: 50-64

Matsui M, Tominaga A, Hayashi T, Misawa Y, Tanabe S (2007) Phylogenetic relationships and phylogeography of Hynobius tokyoensis (Amphibia: Caudata) using complete sequences of cytochrome $b$ and control region genes of mitochondrial DNA. Mol Phylogenet Evol 44: 204-216

Matsui M, Yoshikawa N, Tominaga A, Sato T, Takenaka S, Tanabe $S$, et al. (2008) Phylogenetic relationships of two Salamandrella species as revealed by mitochondrial DNA and allozyme variation (Amphibia: Caudata: Hynobiidae). Mol Phylogenet Evol 48: 84-93

Mihara M, Sakai T, Nakao K, Martins LO, Hosoya K, Miyazaki J (2005) Phylogeography of loaches of the genus Lefua (Balitoridae, Cypriniformes) inferred from mitochondrial DNA sequences. Zool Sci 22: 157-168

Nagasawa K (1997) Fossil whale bones and paleoenvironmental change in Yamagata Prefecture, northeastern Japan. Bull Yamagata Pref Mus 19: 1-14

Nei M (1987) Molecular Evolutionary Genetics. Columbia University Press, New York

Nei M, Tajima F (1981) DNA polymorphism detectable by restriction endonuclease. Genetics 97: 45-63

Rambaut A, Drummond AJ (2009) Tracer ver. 1.5. Available at http:// tree.bio.ed.ac.uk/software/tracer/

Ronquist F, Huelsenbeck JP (2003) MRBAYES 3: Bayesian phylogenetic inference under mixed models. Bioinformatics 19: 1572-1574

Sato I (1943) A Monograph of the Tailed Batrachians of Japan. Nippon Shuppan-sha, Osaka

Sato H (1994) The relationship between late Cenozoic tectonic events and stress fields and basin development in Northeast Japan. J Geophys Res 99: 22261-22274

Schwarz G (1978) Estimating the dimension of a model. Ann Stat 6: 461-464

Sota T, Ishikawa R, Ujiie M, Kusumoto F, Vogler AP (2001) Extensive trans-species mitochondrial polymorphisms in the carabid beetles Carabus subgenus Ohomopterus caused by repeated introgressive hybridization. Mol Ecol 10: 2833-2847

Suzuki, K (1989) On the late Cenozoic tectonic history in the southern part of Northeast Honshu in Japan. Mem Geol Soc Jpn 32 : 97-112

Suzuki H, Yasuda SP, Sakaizumi M, Wakana S, Motokawa M, Tsuchiya K (2004) Differential geographic patterns of mitochondrial DNA variation in two sympatric species of Japanese wood mice, Apodemus speciosus and A. argenteus. Genes Genet Syst 79: $165-176$

Tajima F (1989) Statistical methods to test for nucleotide mutation hypothesis by DNA polymorphism. Genetics 123: 585-595

Takehana Y, Nagai N, Matsuda M, Tsuchiya K, Sakaizumi M (2003) Geographic variation and diversity of the cytochrome $b$ gene in Japanese wild population of medaka, Oryzias latipes. Zool Sci 20: $1279-1291$

Tamura K, Peterson D, Peterson N, Stecher G, Nei M, Kumar S (2011) MEGA5: Molecular evolutionary genetics analysis using maximum likelihood, evolutionary distance, and maximum parsimony methods. Mol Biol Evol 28: 2731-2739

Tanabe AS (2011) Kakusan4 and Aminosan: two programs for comparing nonpartitioned, proportional, and separate models for combined molecular phylogenetic analyses of multilocus sequence data. Mol Ecol Res 11: 914-921

Tominaga A, Matsui M, Nishikawa K, Tanabe S (2006) Phylogenetic relationships of Hynobius naevius (Amphibia: Caudata) as revealed by mitochondrial $12 \mathrm{~S}$ and $16 \mathrm{~S}$ rRNA genes. Mol Phylogenet Evol 38: 677-684

Weisrock DW, Macey JR, Ugurtas IH, Larson A, Papenfuss TJ (2001) Molecular phylogenetics and historical biogeography among salamandrids of the "true" salamander clade: rapid branching of numerous highly divergent lineages in Mertensiella Iuschani associated with the rise of Anatolia. Mol Phylogenet Evol 18: 434-448

Yamaji A, Sato H (1989) Miocene subsidence of the Northeast Honshu Arc and its mechanism. Mem Geol Soc Jpn 32: 339349

Yamamoto S, Morita K, Kitano S, Watanabe K, Koizumi I, Maekawa K, Takamura K (2004) Phylogeography of white-spotted charr (Salvelinus leucomaenis) inferred from mitochondrial DNA sequencies. Zool Sci 21: 229-224

Yoshikawa N, Matsui M, Nishikawa K, Kim JB, Kryukov A (2008) Phylogenetic relationships and biogeography of the Japanese clawed salamander, Onychodactylus japonicus (Amphibia: Caudata: Hynobiidae), and its congener inferred from the mitochondrial cytochrome b gene. Mol Phylogenet Evol 49: 249259

Yoshikawa N, Matsui M, Nishikawa, K (2012) Genetic structure and cryptic diversity of Onychodactylus japonicus (Amphibia, Caudata, Hynobiidae) in northeastern Honshu, Japan, as revealed by allozymic analysis. Zool Sci 29: 229-237

(Received September 11, 2012 / Accepted October 21, 2012) 